\title{
Association between outcome of pregnancy and glycaemic control in early pregnancy in type 1 diabetes: population based study
}

\author{
Rosemary Temple, Vivien Aldridge, Richard Greenwood, Philip Heyburn, Michael Sampson, \\ Katharine Stanley
}

Recent studies of pregnancy in women in the United Kingdom with type 1 diabetes have shown a fourfold to tenfold increased risk of congenital malformation and a fivefold increased risk of perinatal mortality compared with non-diabetic women. ${ }^{12}$ These studies used different measures of glycaemic control (concentrations of glycated haemoglobin and fructosamine) both within and between centres so no conclusions were reached about the relation between outcome and glycaemic control. We conducted a population study examining the relation between glycaemic control in early pregnancy and outcome of pregnancy in women with type 1 diabetes.

\section{Participants, methods, and results}

This observational study was carried out in a single centre in Norwich from January 1991 to December 2000. The resident population is 510000 and mainly white. We defined adverse pregnancy outcome as spontaneous abortion (first or second trimester), major congenital malformation (potentially life threatening or associated with serious long term disability), stillbirth, or neonatal death. We measured glycated haemoglobin concentration at booking for prenatal care and then monthly using the Biomen 8140 method.

Women were divided into two groups according to their glycated haemoglobin concentration at booking; women with values $<7.5 \%$ (mean of normal range plus 5 standard deviations) were defined as having fair control and those with values $\geqslant 7.5 \%$ were defined as having poor control. The study was approved by the local ethics committee.

We included only the first pregnancy for each woman during the study in the statistical analyses to avoid possible biases. We analysed data with SPSS software using Student's $t$ test, Mann-Whitney U test, and $\chi^{2}$ test as appropriate. Fisher's exact test was used for small numbers.

There were 242 pregnancies in 158 women. Thirty two pregnancies had an adverse outcome, with $18(7 \%)$ spontaneous abortions, eight (3\%) major congenital malformations (six neural tube defects), four stillbirths, and two neonatal deaths.

We studied the relation between glycated haemoglobin concentration at booking and adverse outcome in the 158 first pregnancies. The table shows the patient characteristics and pregnancy outcomes. Adverse outcome was significantly higher in the poor control group than the fair control group (relative risk $4.3,95 \%$ confidence interval 1.8 to 10). Compared with the fair control group, the poor control group had a fourfold increase in the spontaneous abortion rate (relative risk 4.0, 1.2 to 13.1) and ninefold increase in the congenital malformation rate (relative risk 9.2, 1.1 to 79.9). Perinatal mortality was higher in the poor control group than the fair control group (54/1000 births $v 19 / 1000$, relative risk $2.8,0.41$ to 19.4 ) but with the small numbers the difference was not significant. Perinatal mortality in the background population is 7.8/1000.

\section{Comment}

We found a significant relation between adverse outcome of pregnancy and poor glycaemic control in early pregnancy in women with type 1 diabetes. There was a fourfold increase in adverse outcome, a fourfold increase in spontaneous abortion, and a ninefold increase in major congenital malformation in women with a glycated haemoglobin concentration above $7.5 \%$ at booking. Our study has substantial advantages over earlier studies, being a complete, prospective, population based, single centre study analysing only one pregnancy per woman. It confirms earlier reports of increased risk of spontaneous abortion and malformation with poor glycaemic control in early pregnancy in women with type 1 diabetes..$^{3-5}$ Our findings suggest that good glycaemic control around the time of conception is necessary to optimise outcome of pregnancy in diabetic women. Diabetic women and their carers need to be advised of the risks and encouraged to optimise glycaemic control before and during pregnancy.

Contributors: RCT had the key idea for the study. All authors contributed to development of the study. RCT and VJA collected data for the study and RCT did the data entry and statistical analysis and compiled the first draft of the manuscript. All authors contributed to interpretation of results and revised critically and approved the final report. We thank Moira Kelly

Characteristics and outcome of pregnancy in women with type 1 diabetes according to glycaemic control at booking. Values are numbers (percentages) of women unless stated otherwise

\begin{tabular}{lccc} 
& $\begin{array}{c}\text { Fair control } \\
\left(\mathbf{H b A}_{\mathbf{1 c}}<7.5 \%\right)\end{array}$ & $\begin{array}{c}\text { Poor control } \\
\left(\mathbf{H b A}_{\mathbf{1 c}} \geqslant \mathbf{7 . 5} \%\right)\end{array}$ & P value \\
\hline No of women & 110 & 48 & \\
\hline Mean (SD) age (years) & $29.0(4.4)$ & $26.2(6.1)$ & 0.007 \\
\hline Mean (SD) weight at booking (kg) & $67.3(10.3)$ & $68.5(10.4)$ & $\mathrm{NS}$ \\
\hline Mean (range) duration of diabetes (years) & $12.0(1-28)$ & $12.5(1-32)$ & $\mathrm{NS}$ \\
\hline Mean (SD) time of booking (weeks) & $7.6(2.4)$ & $8.2(2.5)$ & $\mathrm{NS}$ \\
\hline Primiparous & $76(69)$ & $33(69)$ & $\mathrm{NS}$ \\
\hline Smokers & $21(19)$ & $14(29)$ & $\mathrm{NS}$ \\
\hline Microvascular complications & $13(12)$ & $10(21)$ & $\mathrm{NS}$ \\
\hline Pregnancy outcome: & & & \\
\hline Spontaneous abortion & $4(4)$ & $7(15)$ & 0.019 \\
\hline Major congenital malformation & $1(1)$ & $4(8)$ & 0.03 \\
\hline Stillbirth & $1(1)$ & $1(2)$ & $\mathrm{NS}$ \\
\hline Neonatal death & $1(1)$ & $1(2)$ & $\mathrm{NS}$ \\
\hline Total pregnancy loss & $7(6)$ & $13(27)$ & $<0.0001$ \\
\hline
\end{tabular}

\section{Elsie Bertram \\ Diabetes Centre, \\ Norfolk and \\ Norwich University \\ Hospital NHS \\ Trust, Norwich \\ NR4 7UY \\ Rosemary Temple consultant physicican \\ Vivien Aldridge \\ diabetes nurse \\ specialist \\ Richard \\ Greenwood \\ consultant physician \\ Philip Heyburn \\ consultant physician \\ Michael Sampson \\ consultant physician \\ East Anglia Centre for Fetal and \\ Maternal Medicine, Norfolk and \\ Norwich University \\ Hospital NHS Trust \\ Katharine Stanley \\ consultant \\ obstetrician \\ Correspondence to: R Temple \\ rosemary.temple@ \\ Norfolk-norwich. \\ thenhs.com}

BMJ 2002;325:1275-6 
and Lynettte Yaxley for help in initial development of the study and Michael Grande for statistical advice. RCT is guarantor for the study.

Funding: None.

Competing interests: None declared.

1 Casson IF, Clarke CA, Howard CV, McKendrick O, Pennycook S, Pharoah POD, et al. Outcomes of pregnancy in insulin dependent women: results of a five year cohort study. BMJ 1997;315:275-8.

2 Hawthorne G, Robson S, Ryall EA, Sen D, Roberts SH, Ward Platt MP. Prospective population based survey of outcome of pregnancy in diabetic women: results of the northern diabetic pregnancy audit, 1994. BMJ 1997;315:279-81.

3 Hanson U, Persson B, Thurnell S. Relationship between haemoglobin Alc in early type 1 (insulin-dependent) diabetic pregnancy and the occurrence of spontaneous abortion and fetal malformation in Sweden. Diabetologia 1990;33:100-4

4 Nielson GL, Sorensen PH, Nielson PH, Sabroe S, Olsen J. Glycosylated hemoglobin as predictor of adverse fetal outcome in type 1 diabetic pregnancies. Acta Diabetol 1997;34:217-22

5 Rosenn B, Miodovnik M, Combs CA, Khoury J, Siddiqi TA. Glycaemic thresholds for spontaneous abortions and congenital malformations in insulin-dependent diabetes mellitus. Obstet Gynecol 1994;84:515-20.

(Accepted 22 April 2002)

\title{
Observational study of type of surgical training and outcome of definitive surgery for primary malignant melanoma
}

\author{
Rona M MacKie, Caroline A Bray, David J Hole
}

Department of Public Health, University of Glasgow, Glasgow G12 8RZ

Rona M MacKie Leverhulme

professorial research fellow

Caroline A Bray medical statistician

David J Hole professor of epidemiology and biostatistics

Correspondence to R M MacKie R.M.Mackie@ clinmed.gla.ac.uk

BMJ 2002;325:1276-7
The incidence of primary cutaneous malignant melanoma continues to rise, ${ }^{1}$ coinciding with narrower excision margins of normal skin being recommended around primary melanomas. ${ }^{23}$ The bulk of surgery for primary melanoma is now done on an outpatient basis under local anaesthesia. This change has occurred at a time when training in dermatological surgery has developed, leading to a much higher proportion of excisions of primary melanoma being done by dermatologists. In 1979 in the west of Scotland only 3\% of all primary melanomas were removed by dermatologists. By 1998 this figure had risen to 40\%. Plastic surgeons now excise $26 \%$ of primary melanomas compared with $65 \% 20$ years ago, and general surgeons excise 34\% compared with $32 \%$.

We aimed to establish if the change in type of surgeon removing primary cutaneous malignant melanoma has affected the prognosis, and also whether any evidence exists for a specialist treatment effect such as has been observed for breast cancers, with better outcomes for surgeons carrying out breast cancer surgery regularly. ${ }^{4}$

\section{Participants, methods, and results}

We identified 4159 melanoma patients from the files of the Scottish melanoma group. All patients had had their primary melanoma removed between 1979 and 1998. We divided the surgeons performing the defini- tive excision of the primary melanoma into dermatological, plastic surgery, or general surgery training. We recorded age, sex, tumour thickness, presence of ulceration, and maximum diameter of the primary tumour and noted mortality and cause of death up to 1998. We also looked at the effect within the three surgical groups of treating up to six or more than six primary melanomas annually.

An average of 10 years' follow up information was available for all patients. To test for an association between tumour thickness and type of surgical experience we used the $\chi^{2}$ statistic for trend, aggregated over the period of diagnosis. We used the Cox proportional hazards model to compare the survival of patients in relation to surgical experience, ${ }^{5}$ with adjustment for thickness, ulceration, and maximum diameter of tumour and sex, age, and deprivation category of patients.

The table shows the division of patients by tumour thickness, ulceration, maximum diameter of primary melanoma, and outcome by surgical training. Dermatologists treated a significantly higher proportion of thin melanomas $(\mathrm{P}<0.001)$. The proportion of ulcerated melanomas was higher in the plastic surgery group than in the dermatological group $(\mathrm{P}<0.001)$ and higher in the general surgical group than the plastic surgery group $(\mathrm{P}<0.001)$.

After adjustment for thickness, the best outcome was in the dermatological surgeon treatment group

Details of melanomas treated, by surgical groups adjusted for type of surgical training. Values are numbers (percentages) unless stated otherwise

\begin{tabular}{|c|c|c|c|c|}
\hline Characteristics of melanomas & Dermatologist surgeon $(n=1076)$ & Plastic surgeon (n=1691) & General surgeon $(n=1392)$ & Total $(n=4159)$ \\
\hline Primary tumours $<1.5 \mathrm{~mm}$ thick & $739(69)^{\star}$ & $809(48)$ & $589(42)$ & $2137(51)$ \\
\hline Primary tumours $1.5-3.49 \mathrm{~mm}$ thick & $217(20)$ & $447(26)$ & $342(25)$ & $1006(24)$ \\
\hline Primary tumours $\geqslant 3.5 \mathrm{~mm}$ thick & $120(11)$ & $435(26)$ & $461(33)$ & $1016(24)$ \\
\hline \multicolumn{5}{|l|}{ Relative hazard ratios† (95\% Cl) (risk of death) } \\
\hline Adjusted for thicknessł & 1.0 & 1.33 (1.07 to 1.65$)$ & 1.41 (1.14 to 1.75$)$ & $P=0.008$ \\
\hline Adjusted for thickness and ulceration & 1.0 & $1.22(0.97$ to 1.54$)$ & $1.23(0.97$ to 1.55$)$ & $\mathrm{P}=0.19$ \\
\hline
\end{tabular}

${ }^{*} \mathrm{P}<0.001$ for comparison of proportion of thin melanomas treated by dermatological surgeons compared with other surgeons; also for proportion of ulcerated melanomas both between dermatological and plastic surgeons and between plastic and general surgeons.

†Sex, age, deprivation category, and year of diagnosis were considered in the model but did not contribute any significant impact on surgical training differences.

¥Thickness of primary tumour has been entered as a stratification variable owing to non-proportionality of the hazard functions. 